\title{
Psychomotor Competency Requirements for Public Sector Leaders
}

\author{
Nico Schutte \\ Department of Public Administration, North-West University, Mafikeng Campus, Mmabatho, South Africa, 2745 \\ nico.schutte@nwu.ac.za
}

\section{Doi:10.5901/mjss.2014.v5n27p1025}

\begin{abstract}
South African public sector leaders are currently faced with a rapid changing environment that requires from them to be alert and ready to act. The main objective of this research was to explore the psychomotor competency requirements for leaders in the South African Public sector. A questionnaire was administered among a sample of Public sector managers ( $N=168)$. The respondents perceived that public sector leaders displayed below average affective competencies relating to complex overt response, modus and guided response. Significant large gaps existed between the current displays of the psychomotor competencies versus the importance thereof. Recommendations are made.
\end{abstract}

Keywords: Public sector, strategic leaders, management, affective competencies

\section{Introduction}

South Africa is currently faced with a rapidly changing global world and a subsequent move towards value for money and quick response. This creates a situation whereby current and future public service strategic leaders need to be alert and ready to act. Therefore, a public service without effective strategic leadership, are faced with the possibility not to deliver the expected and promised services against the backdrop of the confronting global challenges. Furthermore, South Africa in general and the public sector specifically has been experiencing major transformation, since 1994.

Moreover, the context within which the public sector in South Africa should function is set out in Section 195(1) of the Constitution of South Africa (South Africa, Act No 108 of 1996), where it is stated that Public administration must be governed by the democratic values and principles enshrined in the Constitution. These include the following principles:

- A high standard of professional ethics must be promoted and maintained.

- Efficient, economic and effective use of resources.

- Public administration must be development-oriented

- Services must be provided impartially, fairly, equitably and without bias.

- People's needs must be responded to, and the public must be encouraged to participate in policy-making.

- Public administration must be accountable.

- Transparency must be fostered by providing the public with timely, accessible and accurate information.

- Good human-resource management and career-development practices, to maximise human potential, must be cultivated.

- Public administration must be broadly representative of the South African people, with employment and personnel management practices based on ability, objectivity, fairness and the need to redress the imbalances of the past to achieve broad representation."

In the light of the above it would be important for the public service to become sensitive to the fact that embedded within the stated principles are specific expectations.

Expectation on the side of the government that the appointed public managers (strategic leaders) are able (competent) and willing (motivated) to deliver (perform) supposed responsibilities as cited by article 195, and expectation on the side of the community that they will receive the promised services as a result of the appointed public managers leadership ability. Furthermore, it is expected of the members of the Senior Management Service (SMS) of the public service to manage and lead their respective institutions within the context of these basic values and principles.

In support, the White Paper on the Transformation of the Public Service (South Africa, 1995) states that institution building and management are part of the creation of a strategic framework for change. Subsequently, the White Paper lists one objective as "empowering, challenging and motivating managers at all levels to be leaders, visionaries, initiators and effective communicators and decision-makers, capable of responding proactively to the challenges of the change 
process, rather than acting as the administrators of fixed rules and procedures" (South Africa, 1995 p., 48 - 51).

Furthermore, does it also recommend that strategies should be developed to deal among other things with new and more participative organisational structures, new organisational cultures, learning organisations, and managing change and diversity.

Nevertheless, in order for the public service to create and as such accomplish the principles as enshrined in the Constitution can only be accomplished through competitive performance in their current organisational settings in addition to the consideration of adequate acquisition, recognition and use of strategic leadership competencies within the top echelons of the public service. Therefore, strategic leadership performance within the public service refers to the ability of the various strategic leaders to achieve the strategic objectives of the public service - is a constantly raising factor in each public service entity. Thus, there is an increased professional organisational and social requirement for encapsulating, storing, exchanging, and managing strategic leadership competencies.

Additionally, Former President Mbeki (2000) also alluded to strategic leadership when he noted that strategic leadership entails: "The training of new leadership which is equipped with functional competence within a particular area of work and at the same time is able to understand the bigger picture. Leaders who has the ability to combine service delivery with strategic vision are the future of our country" (p., 3).

Lockett (1992) indicates that an individual's measurable performance cannot exceed their competence. He further argues that lack of competence (i.e. applied skill and knowledge), is a barrier which may prevent people from reaching a higher level of performance. People cannot perform as well in areas where they have little ability or potential as they can in areas where they have higher levels of skill and knowledge. Competence forms part of a person's capacity to perform.

The main objective of this research was to determine the psychomotor competency requirements for public sector leaders.

\section{Competency and Competency Models}

Lucia and Lepsinger (1999) define a competency as: "... 'a cluster of related knowledge, skills, and attitudes that affects a major part of one's job (a role or responsibility), that correlates with performance on the job, that can be measured against well-accepted standards, and that can be improved via training and development." They further argue that a competency is broader than a skill in that it includes knowledge and it is linked to performance, additionally, it can also be improved on. That's a unique identified competency when treated in isolation. Organisations could even improve more on its performance capability when implementing a competency model, which is the integrated set of competencies required for excellent performance in a specified job.

According to Lockett (1992) Competence "relates to what people need to do to perform effectively in their current role", while competency "relates to the potential to transfer those skills to other areas". In his view, both factors are critical in relation to management of performance. Competence is a necessary condition of performance. People can only perform well if they have the necessary skills and knowledge to do the job.

Competency is a key capability factor. People can only develop new skills if they possess the personal characteristics which can be transferred into higher quality work. It is clear from the argument presented by that over the years; organisations have battled with the holistic implementation of performance management. If only performance appraisal is given priority, then the purpose of performance management and development systems is defeated. More definitions of competencies are reported in Table 1 below.

Table 1: Definitions of the concept competency

\begin{tabular}{|l|l|}
\hline Author & $\begin{array}{l}\text { Concept } \\
\text { Boyatzis (1982) } \\
\text { social role, or a body of knowledge), which results in effective and/or superior performance in a job. }\end{array}$ \\
\hline Bellis (1997 & $\begin{array}{l}\text { Views competence as a skill or cluster of skills, executed within an indicated range or context, and to specific } \\
\text { standards of performance, integrated knowledge, understanding and the ability to transfer the skills to other related } \\
\text { contexts. }\end{array}$ \\
\hline Sparrow (1997) & $\begin{array}{l}\text { Competencies are people's behavioural repertoires, i.e. their sets of behavioural patterns, which are related to work } \\
\text { performance and distinguish excellent from average performers. }\end{array}$ \\
\hline Spencer et al. (1994) & $\begin{array}{l}\text { A competency is a combination of motives, traits, self-concepts, attitudes or values, content knowledge or cognitive } \\
\text { behaviour skills; any individual characteristic that can be reliably measured or counted and that can be shown to } \\
\text { differentiate superior from average performers. }\end{array}$ \\
\hline Woodruffe (2000) & $\begin{array}{l}\text { Competencies are the set of behaviour patterns that the incumbent needs to bring to a position in order to perform } \\
\text { its tasks and functions with competence. }\end{array}$ \\
\hline Brophy and Kiely (2002) & A competency "therefore describes a feature of a person's ability to perform their job effectively" \\
\hline
\end{tabular}


Conversely, Bellis (1997) views competence as a skill or cluster of skills, executed within an indicated range or context, and to specific standards of performance, integrated knowledge, understanding and the ability to transfer the skills to other related contexts. Subsequently, it is anticipated that strategic leaders need to display the necessary work behaviour to perform on the job in pursuit of the organisational vision. Thus, strategic leaders must act or should perform their expected duties in a specific way to accomplish their job responsibilities. It is expected that they should produce quality work, use resources effectively, and follow guidelines and processes to achieve desired results. All behaviour must rise to certain standards. The work produced can also be measured according to a certain amount, completed within a given time frame and according to a specified level of customer satisfaction (Langdon, 2000).

Additionally, a related aspect emerging in the strategic leadership literature is self-efficacy. Self-efficacy refers to individuals' judgments about their perceived capabilities for performing specific tasks. Self-efficacy is the result of life experiences that teach one that one can, in fact, take actions that will effectively have an impact on one's environment, (Bandura, 1997). Wood and Bandura (1989a, p. 48) define self-efficacy as "beliefs in one's abilities to mobilize the motivation, cognitive resources, and courses of action needed to meet situational demands." Research has demonstrated strong positive relationships between self-efficacy and various criteria of human performance in organizations.

Additionally, Prahalad and Hamel (1990) also refers to the term 'core competencies' while Stalk et al. (1992) use the term 'strategic capabilities'. Hence, if the public service is to develop and be sustainable in the longer term, then it needs to develop its strategic capabilities. Vakola et al. (2007) merged several definitions and stated that "an individual job-related competency is the underlying set of behavioural patterns of an employee related to effective and/or superior work performance, acting both at individual and collective level (effective/superior performance both in solitary and interpersonal work), and that provide the organisation in which they are implemented and applied with sustainable competitive advantage." Therefore, the quest for strategic leader competencies by scholars and researchers was an expected evolution of leadership research. In the late 1980s, some scholars and researchers also began to question whether leadership actually bring about the envisaged change in organisations while others suggested that perhaps the study of leadership had reached its satiated point.

However, instead of disappearing, the study of leadership took on a new dynamism with a prominence on leadership of organisations, rather than the traditional leadership approaches that focused on face-to-face interaction at lower organisational levels. Studies of transformational leadership, organisational culture, visionary leadership, organisational change, and charismatic leaders reinvigorated the field of leadership. Thus, the notion of strategic leadership was introduced. Leadership competency models are also used to establish prerequisite criteria and as such improve leadership effectiveness in relation to future organisational challenges. They also provide a common framework for discussing competencies and performance, (Emiliani: 2003).

According to Dubois ( 1993) a competency model are "Those competencies that are required for satisfactory or exemplary job performance within the context of a person's job roles, responsibilities and relationships in an organization and its internal and external environments" ( p., 9). Consequently, a competency model is a descriptive tool that identifies the knowledge, skills, abilities, and behaviour needed to perform effectively in an organization. Designed to help an organisation meet its strategic objectives through building human-resources capability, competency modelling has been in existence since the 1970s, starting with the first models created by David McClelland. Such models gained popularity in the late 1980 s and remain in use today.

Besides, competency models focus on behaviour rather than on personality traits, because personality traits are usually hard to measure accurately. Expressing desirable traits in behavioral terms is essential for a competency model to be useful as a human-resources tool, because the model must not only define the competencies necessary for effective performance but also indicate how to tell when a particular competency is being demonstrated. Most competency models express traits and characteristics in behavioral terms on the grounds that behaviour is the observable manifestation of personality traits and characteristics. Competencies are deemed critical for inclusion in a model when they distinguish superior performers from poor performers.

Subsequently, the main objective of this research is to determine the psychomotor abilities of public sector leaders in the South African context. The first theorist to coin the term 'psychomotor' was Carl Wernicke (1848-1905). Wernicke worked on aphasia (a term he also coined). In support, through the study of aphasia Wernicke revealed how human functioning can be explained by psychosensory input, psychomotor output, and the intrapsychic functions which coordinated the two (Weckowicz, 2010). Furthermore, Wernicke also used the psychological reflex arc proposed by John Dewey in 1896 to explain how humans interact with their environment, by making sense of it, and interpreting such sensory information in an integrated manner.

Hence, psychomotor abilities can be defined as the process of interaction between the perceptual systems (or five senses), the brain (where perceptual information is interpreted) and the body (where the individual reacts to such 
perceptual stimuli). In addition, Tan (2006) explains that 'psycho' refers to the mind or psyche, and 'motor' to the physiological body. Therefore, as Tan (2006) explains with reference to the public service 'psychomotor' can thus be seen as the mind-body interaction, and 'psychomotor abilities', as those abilities which allow for effective interaction between the strategic leadership cognitive job knowledge and the subsequent execution as well as the awareness of their environment (Tan, 2006).

\section{Research Method}

\subsection{Research Approach}

A quantitative research approach was followed using surveys to collect the data. The research was cross-sectional in nature given that the data was collected at one point in time (Field, 2009).

\subsection{Respondents}

The sample included strategic leaders that represent five major central government institutions. A total of 550 questionnaires were administered to senior management of the five mentioned institutions. A total of 168 questionnaires were returned which represent $30.55 \%$ response rate. Most of the respondents were male (57.7\%) and representative of the black ethnic group (54.2\%). The respondents were primarily employed as directors (47\%) and with a national diploma as their highest level of qualification (32.7\%). Most of the respondents' was speaking indigenous languages (39.29\%) as their home language. The demographic characteristics of the respondents are presented in Table 1 below.

\subsection{Measuring Instrument}

A questionnaire was developed to measure the psychomotor competencies of the leaders. The questionnaire consists of 29 items and measure seven dimensions: Perception, Readiness to Act, Guided Response, Mechanism, Complex Overt Response, Adaptation and Origination. A brief description of the dimensions is presented in Table 2 below.

Table 2: Descriptions of Psychomotor Dimensions

\begin{tabular}{|l|l|}
\hline Dimension & Description \\
\hline Perception & $\begin{array}{l}\text { The ability to use sensory cues to guide motor activity. This ranges from sensory stimulation through cue } \\
\text { selection to translation. }\end{array}$ \\
\hline Readiness to Act & $\begin{array}{l}\text { Readiness to act. It includes mental, physical, and emotional sets. These three sets are dispositions that pre- } \\
\text { determine a person's response to different situations (sometimes called mind-sets). }\end{array}$ \\
\hline Guided Response & $\begin{array}{l}\text { The early stages in learning a complex skill that includes imitation and trial and error. Adequacy of performance } \\
\text { is achieved by practicing }\end{array}$ \\
\hline Mechanism & $\begin{array}{l}\text { This is the intermediate stage in learning a complex skill. Learned responses have become habitual and the } \\
\text { movements can be performed with some confidence and proficiency }\end{array}$ \\
\hline Complex Overt Response & $\begin{array}{l}\text { Proficiency is indicated by a quick, accurate and highly coordinated performance, requiring a minimum of } \\
\text { energy. }\end{array}$ \\
\hline Adaptation & Skills are well developed and the individual can modify movement patterns to fit special requirements. \\
\hline Origination & $\begin{array}{l}\text { Creating new movement patterns to fit a particular situation or specific problem. Learning outcomes emphasise } \\
\text { creativity based upon highly developed skills. }\end{array}$ \\
\hline
\end{tabular}

The questionnaire uses a dual scale. Respondents are first required to indicate the extent of their agreement with each statement on a five-point Likert-type scale ranging from very dissatisfied (1) to very satisfied (5). Respondents are secondly required to indicate the importance of the talent management practices from Not Important (1) to Very Important (5).

\subsection{Statistical Analyses}

Statistical analysis was carried out using the SPSS Program (SPSS Inc, 2014). The reliability and validity of the Psychomotor Competency Measure was determined by means of exploratory factor analysis and Cronbach alpha coefficients. Effect sizes (Steyn, 1999) were used to decide on the practical significance of the findings. For purposes of this research we used Cohen's (1988: 283) guidelines for the interpretation of effect sizes: 0.0099 constitutes a small 
effect, 0.0588 a medium effect and 0.1379 a large effect.

\section{Results}

Prior to factor analyses a Kaiser-Meyer-Olkin (KMO) test was done to determine the sample adequacy of the psychomotor competency measure. The psychomotor measure obtained a sample adequacy of 0.963 which are adequate for factor analyses (see Hair, Black, Babin \& Anderson, 2010). Exploratory factor analyses using Principal Axis Factoring analyses were done on the 29 items of the psychomotor competencies measure. The initial analyses showed three distinctive factors. Principal Axis analyses were done using Varimax rotation. The analyses resulted in three factors which explained $92.979 \%$ of the variance. The three factors were labelled: Internalising (Factor 1), Organising Influencing (Factor 2) and Valuing Political Awareness (Factor 3). The results of the rotated factor matrix are reported in Table 3 below.

Table 3: Rotated Factor Matrix of the Psychomotor Competency Scale

\begin{tabular}{|c|c|c|c|}
\hline & \multicolumn{3}{|c|}{ Factor } \\
\cline { 2 - 4 } & Complex Overt Response & Modus & Guided Response \\
\hline P1 & .666 & .528 & .437 \\
\hline P2 & .518 & .677 & .429 \\
\hline P3 & .628 & .437 & .598 \\
\hline P4 & .738 & .403 & .501 \\
\hline P5 & .524 & .470 & .651 \\
\hline P6 & .765 & .404 & .383 \\
\hline P7 & .476 & .610 & .561 \\
\hline P8 & .761 & .436 & .400 \\
\hline P9 & .619 & .437 & .605 \\
\hline P10 & .741 & .515 & .314 \\
\hline P11 & .780 & .428 & .389 \\
\hline P12 & .561 & .515 & .583 \\
\hline P13 & .511 & .473 & .656 \\
\hline P14 & .388 & .679 & .578 \\
\hline P15 & .709 & .466 & .437 \\
\hline P16 & .648 & .445 & .567 \\
\hline P17 & .499 & .712 & .373 \\
\hline P18 & .521 & .476 & .584 \\
\hline P19 & .574 & .439 & .643 \\
\hline P20 & .579 & .665 & .320 \\
\hline P21 & .637 & .413 & .591 \\
\hline P22 & .415 & .767 & .439 \\
\hline P23 & .380 & .602 & .578 \\
\hline P24 & .401 & .742 & .483 \\
\hline P25 & .495 & .685 & .400 \\
\hline P26 & .369 & .636 & .631 \\
\hline P27 & .532 & .744 & .324 \\
\hline P28 & .555 & .540 & .533 \\
\hline P29 & .470 & .541 & .631 \\
\hline & & & \\
\hline
\end{tabular}

The descriptive statistics and reliabilities of the factors of the psychomotor competency measure are reported in Table 4 below. The results show excellent reliabilities for all three factors of the psychomotor Competency Measure. From the mean scores it is evident that that respondents display below average levels of psychomotor competencies in the public sector. 
Table 4: Descriptive statistics and reliabilities for the Psychomotor Competency Scale

\begin{tabular}{|l|c|c|c|c|c|}
\hline & Mean & SD & Skewness & Kurtosis & a \\
\hline Psychomotor Domain & 2.9942 & .82752 & .008 & .099 & .981 \\
\hline Complex Overt Response & 2.8553 & .87603 & .100 & -.069 & .991 \\
\hline Modus & 3.1551 & .86781 & -.069 & -.058 & .989 \\
\hline Guided Response & 2.9721 & .78295 & -.016 & .438 & .981 \\
\hline
\end{tabular}

In order to determine the normality of the scales obtained in the factor analysis, the Kolmogorov-Smirnov test was performed on the Psychomotor Competency Measure, the results of which are reported in Table 5 below. This table indicates that the scale conforms to normality. The Z-statistic is 0.132 , which is greater than 0.05 , which means that the scale is normally distributed. Unlike most statistical testing, a non-significant result is sought-after here.

Table 5: One-Sample Kolmogorov-Smirnov Test

\begin{tabular}{|l|l|c|}
\hline \multicolumn{2}{|c|}{} & \multicolumn{1}{|c|}{ Psychomotor } \\
\hline $\mathrm{N}$ & Mean & 167 \\
\cline { 2 - 3 } Normal Parameters ${ }^{\mathrm{a}, \mathrm{b}}$ & Std. Deviation & 2.9942 \\
\hline \multirow{3}{*}{ Most Extreme Differences } & Absolute & .82752 \\
\cline { 2 - 3 } & Positive & .102 \\
\cline { 2 - 3 } & Negative & .079 \\
\hline \multicolumn{2}{|l|}{} & -.102 \\
\hline Test Statistic & .102 \\
\hline Asymp. Sig. (2-tailed) & $.000^{c}$ \\
\hline
\end{tabular}

Finally univariate analyses were performed to determine whether significant gaps exist between the current versus the importance of the dimensions of the Psychomotor Competency Measure. The results revealed that significant gaps exist between the current demonstrations of psychomotor competencies by business leaders versus the importance thereof. All the effects were medium. The results are reported in Table 6 below.

Table 6: Current display versus the importance of Psychomotor Competencies

\begin{tabular}{|l|c|c|c|c|c|}
\cline { 2 - 6 } \multicolumn{1}{c|}{} & \multicolumn{2}{c|}{ Mean } & Gap & $p$ & Eta \\
\hline Factors & Current & Importance & & & \\
\hline Psychomotor Domain & 2.994 & 4.605 & -1.610 & .000 & .934 \\
\hline Complex Overt Response & 2.855 & 4.595 & -1.740 & .000 & .866 \\
\hline Modus & 3.155 & 4.621 & -1.465 & .000 & .786 \\
\hline Guided Response & 2.972 & 4.598 & -1.626 & .000 & .751 \\
\hline
\end{tabular}

\section{Conclusion}

Competencies in the psychomotor domain focus on the coordination of mental activity with physical movement involved in the doing or performing of a task. Strategic leaders are demonstrating the development of dexterity or manipulative skills, and are executing skills in the performance of their job.

There are a number of variations of the levels of this domain, as different researchers have put forth their best work on refining the taxonomy. The model utilizes the following levels in the psycho-motor domain: Perception, Readiness to Act, Guided Response, Mechanism, Complex Overt Response, Adaptation, and Origination.

Therefore, if the public service commit to expected proficient performance by its strategic leadership, the public service could decide to track, identify and process psychomotor competencies and skills, through which it can achieve transparency about the effective conduct of its strategic leaders. The public service therefore, can develop a common language in the case of its variety of public service institutions to effectively communicate amongst the multiple locations, and the public service's strategic leaders can benefit from the adoption of a reliable strategic leadership job performance classification across all institutions.

The hope is that widespread acceptance of applying the psychomotor competencies will foster standard job performance expectations and action amongst public service institutions and provide a framework to develop new 
efficiencies for public service strategic leaders.

Therefore, for the public service to become an effective and efficient service delivery organisation it need to balance the need to maximise current strategic leadership psychomotor ability with the need to develop its strategic leaders psychomotor proficiency for the future.

Strategic leaders therefore, need to apply two aspects - coordination of mental activity cognitive ability with physical movement -psychomotor output, i.e. demonstrating the enactment of dexterity or manipulative skills, in the performance of their organisational objectives.

Therefore, the public service as Drucker (1993) explained will be judged on its strategic leadership skills and as he further maintained could not be explained in words, it could only be demonstrated and in this case by its strategic leaders.

\section{References}

Bellis, I. (1997). An interpretation of competence. People Dynamics.15 (1), 32-33

Boyatzis, R. E. (1982). The Competent Manager: A Model for Effective Performance. New York: John Willey \& Sons.

Brophy, M. and Kiely, T. 2002. "Competencies: a new sector", Journal of European Industrial Training, 26(2/3/4): 165-176.

Drucker, P. F. (1993). Postcapitalist Society. New York: HerperCollins Publishers.

Dubois, D. D. (1993). Competency-Based Performance Improvement: A Strategy for Organizational Change. HRD Press, Inc., 22 Amherst Road, Amherst, MA 01002.

Emiliani, M. L. (2003), "Linking leaders' beliefs to their behaviors and competencies", Management Decision, Vol. 41 No. 9, pp. 893-910.

Lockett, J., 1992: Effective Performance management: A strategic Guide to Getting the Best from People. Kogan Page, London.

Langdon, D. (2000). Aligning performance: Improving people, systems and organizations. San Francisco: Jossey-Bass/Pfeiffer.

Lucia, A. D. \& Lepsinger, R. (1999). The Art and Science of Competency Models: Pinpointing Critical Success Factors in Organizations. San Francisco: Jossey-Bass/Pfeiffer.

McLagan, P. A. (1989). Models for HRD Practice. Training and Development Journal, 43(9), 49-59.

Mbeki, T. 2000. Speech at the Launch of the Presidential Strategic Leadership Development Programme PRETORIA

Prahalad, C. K., \& Hamel, G. (1990). The core competence of the corporation. Boston (MA), 235-256.

South Africa, 1995b. Ministry for the Public Service and Administration. White Paper on the Transformation of the Public Service. In Government Gazette. No. 16838. 24 November 1995. Pretoria: Government Printer.

Sparrow, P.R. (1997). Organisational competencies: creating a strategic behavioural framework for selection and assessment. In N. Anderson \& P. Herriot (Eds.) International Handbook of Selection and Assessment, Chichester: John Wiley. Pp.343-368.

Spencer, L. M., McClelland, D. C., \& Spencer, S. (1994). Competency assessment methods: History and state of the art. Boston: HayMcBer Research Press.

Simpson E. J. (1972). The Classification of Educational Objectives in the Psychomotor Domain. Washington, DC: Gryphon House.

Tan, Ü. (2006). Psychomotor theory: Mind-brain-body triad in health and disease. NeuroQuantology, 4(2), 101-133.

Vakola, M., Soderquist, K. E., \& Prastacos, G. P. (2007). Competency management in support of organisational change. International Journal of Manpower, 28(3/4), 260-275.

Weckowicz, T. E. (2010). A history of great ideas in abnormal psychology. Mahwah, NJ: Elsevier Publishers.

Wood, R., \& Bandura, A. (1989). Social cognitive theory of organizational management. Academy of management Review, 14(3), 361384.

Woodruffe, C (2000) Development and assessment centers: identifying and developing competence, 3rd edition, Institute of Personnel and Development. 